\title{
Effect of the Annealing Temperature on the Structure and Magnetic Properties of 2\% Si Steel
}

\author{
Marco A. da Cunha, Sebastião C. Paolinelli* \\ Acesita S.A. - Praça Primeiro de maio, 9, 35180-018 Timóteo - MG, Brazil
}

Received: September 27, 2001; Revised: July 10, 2002

\begin{abstract}
To study the effect of the annealing temperature on the structure and magnetic properties of a $2 \% \mathrm{Si}$ non-oriented steel cold rolled samples were submitted to final annealing in the temperature range of $540{ }^{\circ} \mathrm{C}$ to $980^{\circ} \mathrm{C}$ in hydrogen atmosphere. The samples had received cold rolling reduction of $75 \%$ to a final thickness of $0.50 \mathrm{~mm}$. Recovery and recrystallization resulted in significant improvement of magnetic properties, with decrease of iron loss $\left(\mathrm{W}_{1.5}\right)$ and increase of polarisation $\left(\mathrm{J}_{50}\right)$ and relative permeability $\left(\mu_{1.5}\right)$. On further grain growth, after recrystallization, there was simultaneous decrease of iron loss, polarisation and relative permeability. Texture evolution on grain growth accounts for the observed decrease of $\mathrm{J}_{50}$ and $\mu_{1.5}$. The beneficial effect of increasing grain size on core loss overcomes the detrimental effect of texture resulting in decrease of $\mathrm{W}_{1.5}$.
\end{abstract}

Keywords: silicon steel, magnetic properties, recrystallization, texture

\section{Introduction}

In many applications of non-oriented grain silicon steels low iron loss and high permeability are important requirements. It is well known that the magnetic properties are determined by factors such as: composition of the steel, purity level, grain size, strain, crystallographic texture, surface oxidation. The polarisation measured at $5000 \mathrm{~A} / \mathrm{m}\left(\mathrm{J}_{50}\right)$ is strongly dependent on crystallographic texture. The relative permeability at $1.5 \mathrm{~T}\left(\mu_{1.5}\right)$ is strongly dependent on texture, but is also affected by cutting stress, grain size, surface oxidation and nitration. The grain size obtained in the final annealing is one of the most important factors determining iron loss. To optimise the magnetic properties it is important to understand its evolution in the final annealing. The purpose of the present work was to investigate the evolution of the structure, texture and the magnetic properties in the final annealing.

\section{Experimental Procedure}

Cold rolled samples of a $2 \%$ Si steel $0.50 \mathrm{~mm}$ thick were used in this investigation. The samples were taken from industrial production and had received cold rolling reduction of $75 \%$. Final annealing was carried out in a continuous annealing furnace, under hydrogen atmosphere, at temperatures in the range of $540{ }^{\circ} \mathrm{C}$ to $980{ }^{\circ} \mathrm{C}$. The final structure was characterised by optical microscopy and the texture was analysed by X-ray diffraction, at an intermediate position between centre and surface, and by EBSD at a longitudinal section, across the whole thickness. Magnetic properties, iron loss at $1.5 \mathrm{~T}$ and $60 \mathrm{~Hz}\left(\mathrm{~W}_{1.5}\right)$, polarisation $\mathrm{J}_{50}$ and relative permeability $\mu_{1.5}$, were measured in the rolling direction on as sheared samples $305 \times 30 \mathrm{~mm}$, using a single sheet tester.

\section{Results}

\section{Structure and Texture}

The micrograph in Fig. 1 shows the microstructure of the sample annealed at $660{ }^{\circ} \mathrm{C}$. At this temperature nucleation is observed inside the high Taylor factor grains, that appear dark in the microstructure ${ }^{1}$. Nucleation in shear bands, inclined approximately $20^{\circ}$ with the rolling direction, is observed in some grains, as indicated by the arrow in the micrograph. At temperatures below $660^{\circ} \mathrm{C}$ the microstructure is formed by deformed grains with larger elongated grains in the centre than in the surface region. At $700{ }^{\circ} \mathrm{C}$ recrystallization is almost complete and only a few

*e-mail: scpaolinelli@acesita.ind.br 


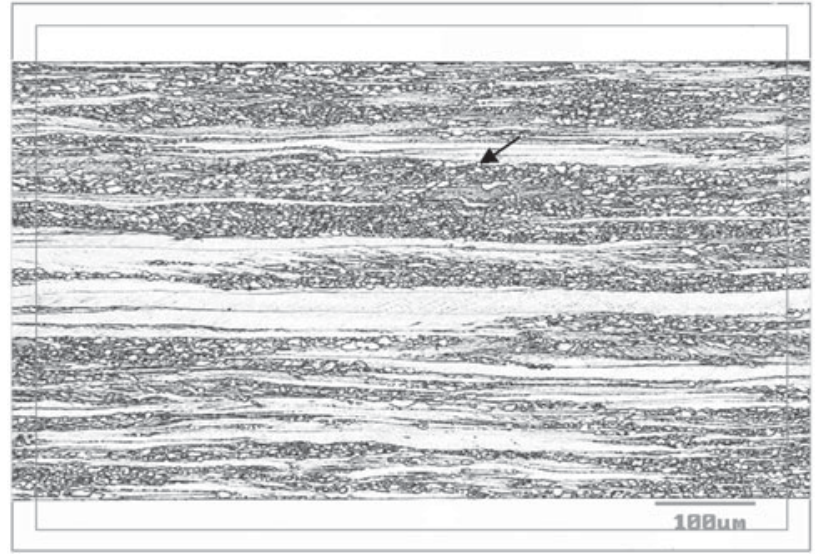

Figure 1. Typical microstructures for the sample annealed at $660{ }^{\circ} \mathrm{C}$.

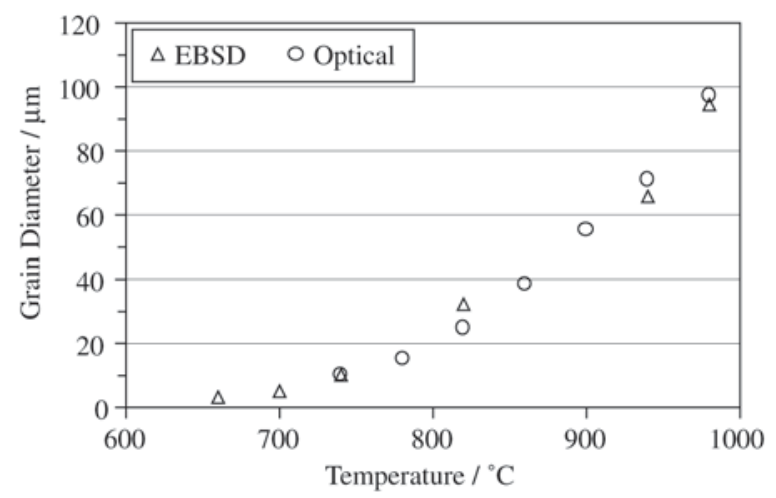

Figure 2. Average recrystallized grain diameter as a function of the annealing temperature. Grain diameter was measured by optical metallography using a Leco image analysis software and by EBSD using Edax-TSL OIM Analysis 3 software.

deformed grains remain, particularly in the centre region. Some non-uniformity in grain size distribution is observed at $700{ }^{\circ} \mathrm{C}$ due to the growth of recrystallized grains at the expenses of low Taylor factor deformed grains. At $740{ }^{\circ} \mathrm{C}$ recrystallization is complete and some further grain growth has occurred. The Average recrystallized grain size is shown in Fig. 2 as a function of the annealing temperature.

The textures measured for the samples annealed at $540{ }^{\circ} \mathrm{C}$ and $700{ }^{\circ} \mathrm{C}$ are shown in Figs. $3 \mathrm{a}$ and $3 \mathrm{~b}$. The textures are represented in ODF sections of $\varphi_{2}=0^{\circ}$ and $\varphi_{2}=45^{\circ}$, Bunge notation. A key to the position of the main orientations is shown in Fig. 3c. The initial texture, Fig. 3a, has components of the $\alpha$ fibre (direction [110] parallel to the rolling direction - RD) and $\gamma$ fibre (direction [111] parallel to the normal direction - ND) with the highest intensities in orientations of the $\alpha$ fibre. Similar results on silicon steels have been reported by others ${ }^{2,3}$. With recrystallization there is a general weakening of the texture. The effect of increasing the random component of the texture is evidenced by the sharp drop in the ODF maximum intensity in Fig. 4. With further grain growth, after recrystallization, there is a strengthening of the texture again, up to $900{ }^{\circ} \mathrm{C}$.

With recrystallization there is an increase in intensities of components of the $\eta$ fibre ([100]||RD) and the maximum intensity peak shifts from the $\alpha$ to the $\gamma$ fibre, close to (111)[112]. The intensity of the $\alpha$ fibre is significantly reduced and the $\gamma$ fibre becomes the main texture. That can be more clearly seen on Fig. 5, that shows the volume fraction of the main texture fibres as a function of the annealing temperature. Further grain growth strengthens the main texture, and reduces the intensities along the $\eta$ and $\alpha$ fibres.

\section{Magnetic Properties}

Figure 6 shows the magnetic properties as a function of the annealing temperature. The effect of the different stages of recovery, recrystallization and grain growth on the magnetic properties can be clearly seen. Recovery, between $540{ }^{\circ} \mathrm{C}$ and $620^{\circ} \mathrm{C}$, results in a steady improvement of magnetic properties. With recystallization there is a sharp decrease of iron loss and increase of $\mathrm{J}_{50}$ and $\mu_{1.5}$ between $620^{\circ} \mathrm{C}$ and $740{ }^{\circ} \mathrm{C}$. At this stage the deformation substructure is consumed and a more random texture is formed. Further grain growth results in decrease of iron loss and also decrease of $\mathrm{J}_{50}$ and $\mu_{1.5} . \mathrm{J}_{50}$ is maximum at $740{ }^{\circ} \mathrm{C}$ and $\mu_{1.5}$ is maximum at $780^{\circ} \mathrm{C}$. The iron loss $\mathrm{W}_{1.5}$ is strongly affected by grain size, and so decreases with the annealing temperature. Polarisation $\mathrm{J}_{50}$ is strongly dependent on texture and decreases with the strengthening of the $\gamma$ fibre, being maximum at the temperature of complete recrystallization. Around $900{ }^{\circ} \mathrm{C}$ it tends to increase again with the weakening of the texture. The relative permeability $\mu_{15}$ shows maximum at a slightly higher temperature than $\mathrm{J}_{50}$. This behaviour has also been observed in other experiments, in which cutting stresses were absent, and has been attributed to a combined effect of grain size and texture. Increasing grain size has a beneficial effect on $\mu_{15}$ that might explain the shift in the maximum to a higher temperature. The detrimental effect of cutting stresses on $\mu_{1.5}$ increases with the grain size, as shown in Fig. 7. It adds to the effect of strengthening the $\gamma$ fibre texture with temperature, contributing to decrease $\mu_{1.5}$ continuously.

\section{Discussion}

\section{Texture Evolution on Recrystallization and Grain Growth}

Samples annealed at $660^{\circ} \mathrm{C}$ and $700{ }^{\circ} \mathrm{C}$ were analysed by EBSD and the orientation distributions of the recrystallized grains are shown in Figs. 8a to 8b. More than 1000 recrystallized grains were observed in each sample. 
(a)

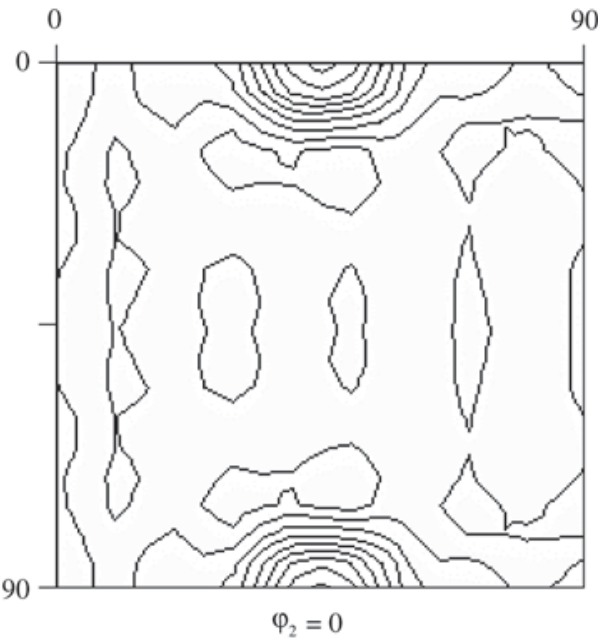

(b)

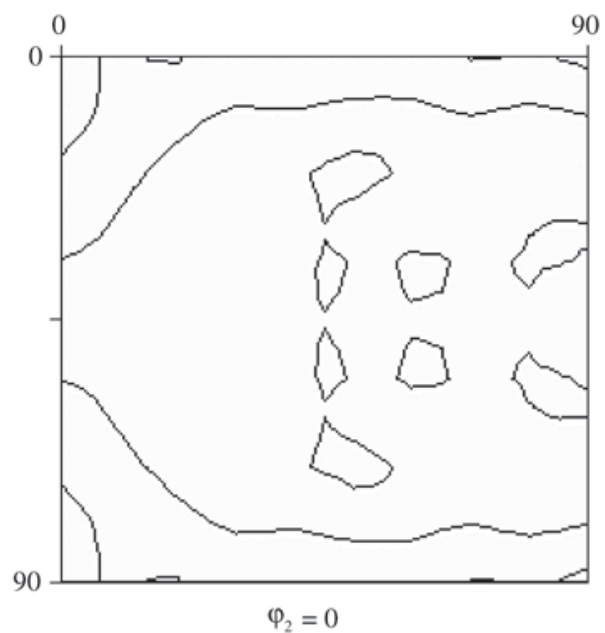

(c)

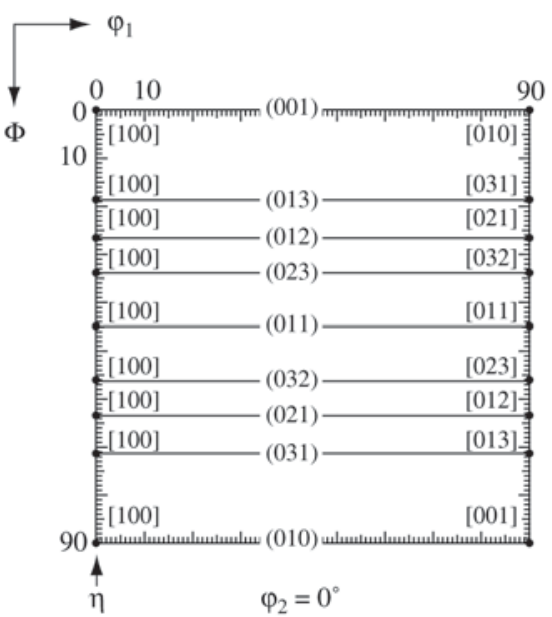

90
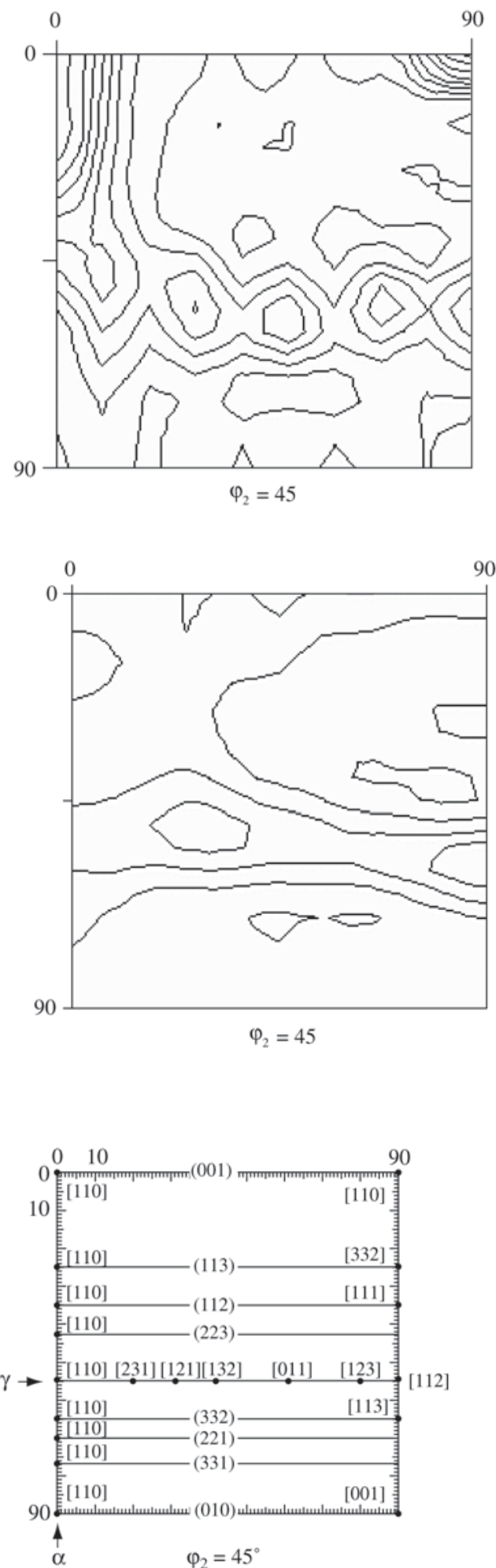


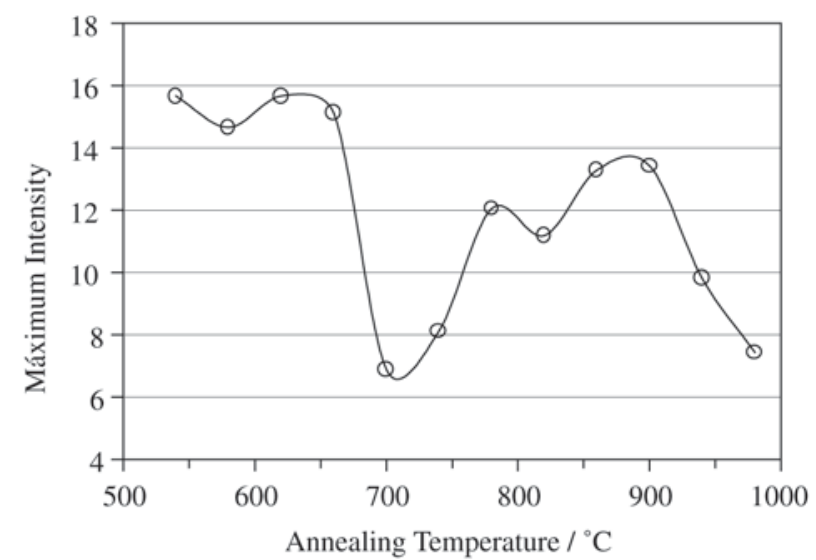

Figure 4. Maximum intensities of the ODF as a function of the annealing temperature.

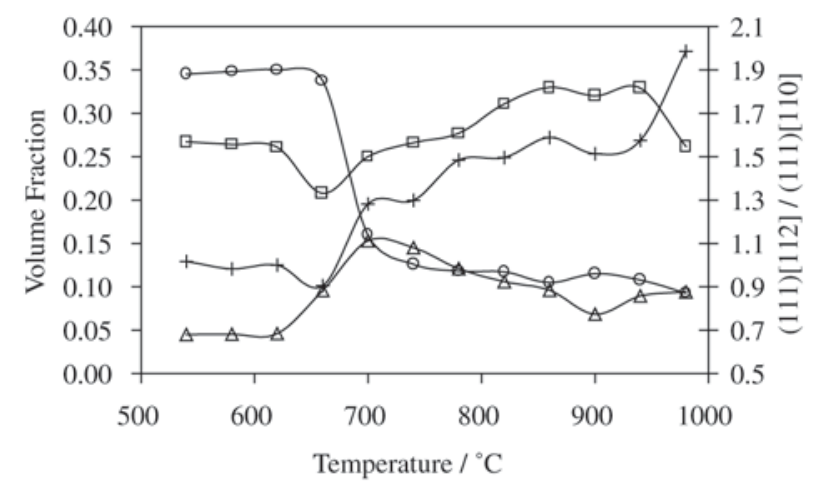

\begin{tabular}{|c|c|}
\hline $\begin{array}{l}\square \text { Alfa Fibre } \\
\triangle-\text { Eta Fibre }\end{array}$ & $\begin{array}{l}\text { घ- Gamma Fibre } \\
\square-(111)[112] /(111)[110]\end{array}$ \\
\hline
\end{tabular}

Figure 5. Volume fractions of the main fibres $(\alpha, \eta, \gamma)$ and ratio between the volume fractions of (111)[112] and (111)[110] as a function of the annealing temperature. The volume fractions were calculated within $15^{\circ}$ around the ideal orientations. The a fibre values plotted represent the volume fractions of $\alpha$ fibre $(\Phi=0$ to $90^{\circ}$ ) minus the volume fractions of (111)[110].

The orientation distributions were calculated by the binning method with $5^{\circ}$ resolution.

At $660{ }^{\circ} \mathrm{C}$ nucleation occurs mainly in the high Taylor factor $\gamma$ fibre grains and the nuclei have a weak texture with high intensity peaks at (111)[112], (225)[110] ( $\alpha$ fibre at $\Phi=30^{\circ}$ ) and along the $\eta$ fibre (particularly between (110)[001] and (210)[001] and at (100)[001]). That explains the reduction in the volume fraction of $\gamma$ fibre in the beginning of recrystallization in Fig. $5^{4}$. It is known that nuclei with Goss orientation are formed mainly at in-grain shear bands in (111)[112] deformed grains ${ }^{5}$. For that reason the volume fraction ratio between (111)[112] and (111)[110],

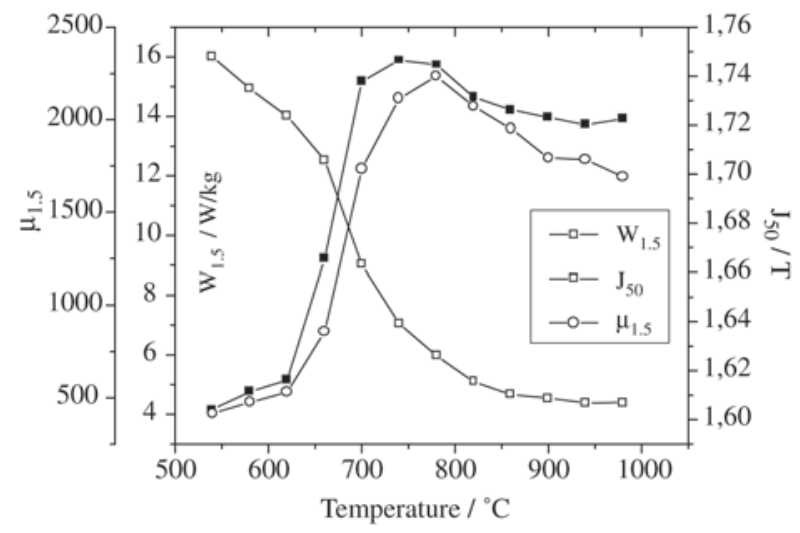

Figure 6. Core loss $\left(\mathrm{W}_{1.5}\right)$, polarisation $\left(\mathrm{J}_{50}\right)$ and relative permeability $\left(\mu_{1.5}\right)$ as a function of the annealing temperature.

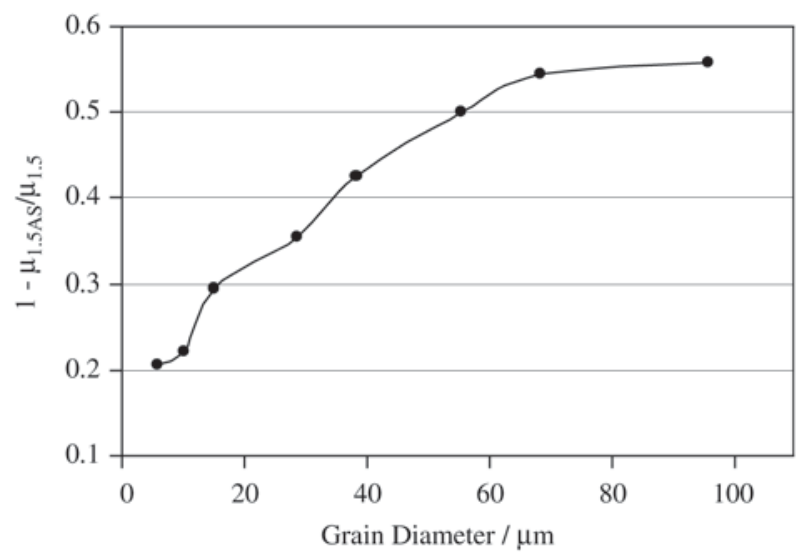

Figure 7. Relative permeability $\left(\mu_{1.5}\right)$ decrease due to cutting stress as a function of grain size. $\mu_{1.5 \mathrm{AS}}$ is the permeability of samples annealed and cut afterwards in the dimensions $305 \times 30 \mathrm{~mm}$ (as sheared); $\mu_{1.5}$ is the permeability of specimens previously cut in the dimensions of the test and then annealed.

shown in Fig. 5, also decreases with the beginning of recrystallization. The EBSD results, however, show that along the $\gamma$ fibre there is preferential nucleation of (111)[112]. These results are consistent with previous studies in low carbon and extra low carbon steels that relate (111)[112] nucleation with the presence of strong $\alpha$ fibre in the deformation texture ${ }^{3,6}$.

Further nucleation favours the high Taylor factor orientations and the $\eta$ fibre. At $700{ }^{\circ} \mathrm{C}$, at a more advanced stage of recrystallization, the $\gamma$ fibre is well defined, with high intensity peak at (111)[112] and minor peak at (111)[110]. Along the $\eta$ fibre the high intensity shifts to (410)[001]. At this temperature recrystallized grains have grown and partially consumed the low stored energy $\alpha$ fi- 

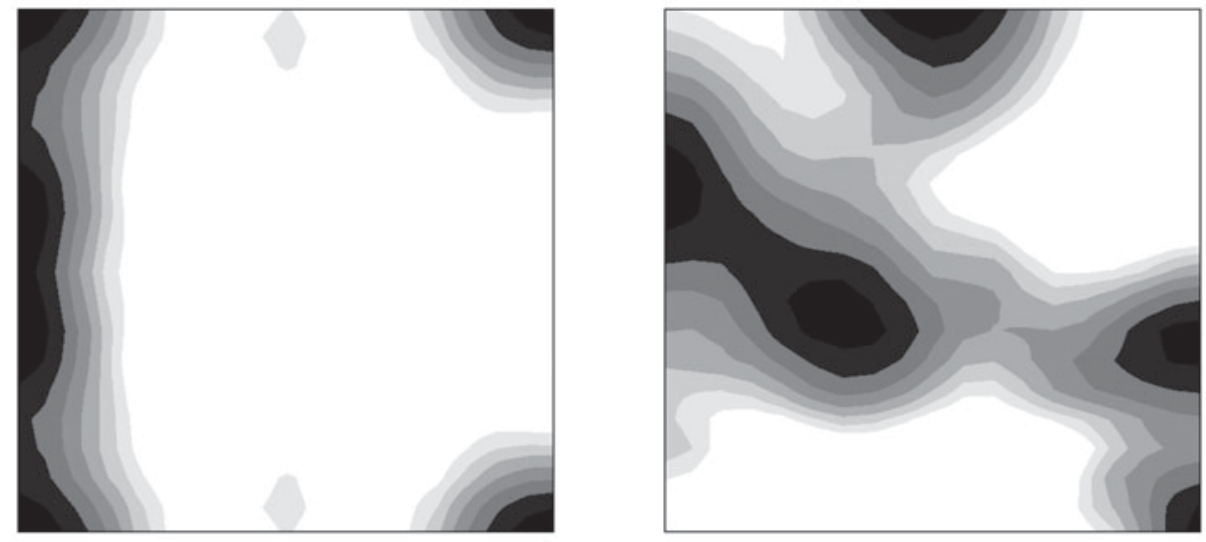

(a)
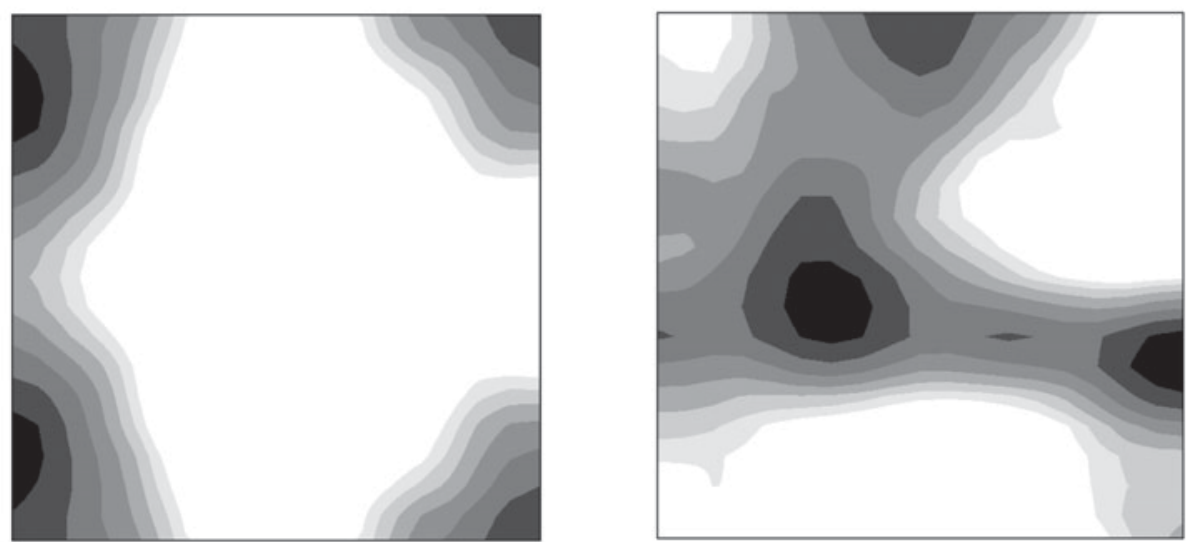

(b)

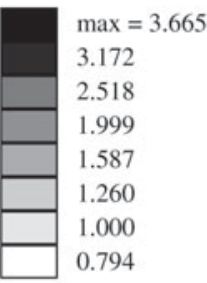

Figure 8. $\varphi_{2}=0^{\circ}$ and $\varphi_{2}=45^{\circ}$ ODF sections, Bunge notation, for recrystallized grains of specimens annealed at: a) $660{ }^{\circ} \mathrm{C}$ and b) $700{ }^{\circ} \mathrm{C}$. Data obtained by EBSD; ODF calculated by the binning method with $5^{\circ}$ resolution.

bre deformed grains, causing the volume fraction of the $\alpha$ fibre in Fig. 5 to decrease significantly. The increase in volume fraction of $\gamma$ fibre above $660^{\circ}$ results from further nucleation and growth. The volume fraction ratio between (111)[112] and (111)[110] increases significantly, as a consequence of preferential nucleation. At this stage there is no grain size advantage of (111)[112] over (111)[110] but the number of grains per square millimetre of (111)[112] is around 65\% higher than that of (111)[110].

Further grain growth after recrystallization strengthens the texture and the $\gamma$ fibre volume fraction continues to increase (particularly the volume fraction of (111)[112]) at the expenses of other orientations such as $\eta$ and $\alpha$ fibre. The strengthening of the $\gamma$ fibre on grain growth has been reported on low carbon steels ${ }^{4}$ and attributed to the growth of larger grains consuming the smaller ones. In the present work, however, $\gamma$ fibre grains, particularly (111)[112] grains, show no size advantage at $740{ }^{\circ} \mathrm{C}$, when some normal grain growth seems to have already occured.

\section{Magnetic Properties}

The ideal combination of magnetic properties would require increasing polarisation and permeability and decreasing iron loss with the annealing temperature. Grain growth after recystallization has a beneficial effect on core loss and $\mu_{1.5}$ The recrystallization texture and its evolution on grain growth have an important effect on the magnetic properties. The effect of an adverse evolution of texture on core loss has been shown to be overcome by the beneficial effect of increasing grain size. The effects of texture and cutting stress on $\mu_{1.5}$ are more significant and determine its behaviour. $\mathrm{B}_{50}$ is known to be strongly dependent on texture and after recrystallization is controlled by texture evolution. In another recent paper the authors have shown that beneficial texture evolution after recrystallization can be obtained by two stages of cold rolling with an intermediate annealing, resulting in reduction of core loss and simultaneous increase of $\mathrm{B}_{50}$ and $\mu_{1.5}{ }^{7}$. 


\section{Conclusions}

The annealing study of a $2 \%$ Si non-oriented steel, after $75 \%$ cold rolling reduction, showed that recovery and recrystallization result in remarkable improvement of magnetic properties. Iron loss $\left(\mathrm{W}_{1.5}\right)$ is reduced, polarisation and permeability are increased $\left(J_{50}, \mu_{1.5}\right)$. Further grain growth results in decrease of iron loss and also decrease of polarisation and permeability, due to the strengthening of the texture where $\gamma$ fibre is the main component. The reduction of $\mu_{1.5}$ with grain growth is more significant due to the additional effect of cutting stress.

\section{Acknowledgements}

The authors gratefully acknowledge the assistance of T.R. Oliveira and P.E.F. Cortes.

\section{References}

1. Hutchinson, B. Phil. Trans. R. Soc. Lond. A, v. 357, p. 1471-1485, 1999.

2. Tchiptchin, A.P.; Santos, C.P.; Cunha, M.A.; Lima, N.B. Proceedings $55^{\circ} \mathrm{ABM}$ Congress, Rio de Janeiro, p 14611470, July 2000.

3. Ray, R.K.; Jonas, J.J.; Hook, R.E. International Materials Reviews, v. 39, n. 4, p. 129-172, 1994.

4. Hutchinson, B. International Materials Reviews, v. 29, n. 1, p. 25-42, 1984.

5. Haratani, T.; Hutchinson, W.B.; Dillamore, I.L.; Bates, P. Metal Science, v. 18, p. 57-65, 1984.

6. Barnett, M.R.; Kestens, L. ISIJ International, v. 39, n. 9, p. 923-929, 1999.

7. Cunha, M.A.; Paolinelli, S.C. $15^{\text {th }}$ Soft Magnetic Materials Conference-SMM, Bilbao (Spain), September 2001, in press. 